\title{
Serum Ferritin Levels in Patients of Chronic Kidney Disease on Hemodialysis: A Need to Redefine Cutoff for Iron/Erythropoietin Therapy
}

\author{
${ }^{1}$ Meghana K Padwal, ${ }^{2}$ Annapurna V Raichurkar, ${ }^{3}$ Rajani R Melinkeri
}

\begin{abstract}
Introduction: Anemia is the common complication of chronic kidney disease (CKD) that mainly affects patients on hemodialysis therapy. The most precise tool to evaluate body iron stores is the measurement of serum ferritin levels. However, serum ferritin is also an acute phase reactant, and its levels may be influenced by inflammation.
\end{abstract}

Objectives: (1) To measure serum ferritin and C-reactive protein (CRP) in the study group; (2) To correlate the levels of serum ferritin and CRP in patients on hemodialysis; (3) To establish a cutoff value for serum ferritin in patients of CKD on hemodialysis receiving Iron/EPO therapy.

Materials and methods: The study participants $(n=240)$ were divided into three groups as group I: Total 80 cases of CKD on hemodialysis receiving iron/erythropoietin (EPO) therapy, Group II: Total 80 cases of CKD on hemodialysis not receiving iron/erythropoietin (EPO) therapy, and Group III: Age and gender-matched 80 healthy controls. Estimation of serum ferritin was done by automated chemiluminescent microparticle immunoassay (CMIA) and CRP by immunoturbidimetric technique.

Results: We observed a statistically significant rise in serum ferritin Group I (1957.6 \pm 714.1), Group II (1063.5 \pm 478.6) as compared to Group III $(101.21 \pm 60.29)$ and CRP levels in group I (104.6 \pm 70.8$)$ as compared to group II $(74.9 \pm 55.8)$ and $(3.7 \pm 0.9)(p<0.005)$. There is a significant positive correlation between ferritin and CRP $(p<0.005)$.

Conclusion: High ferritin levels can be because of both increased iron stores and inflammation which may be associated with erythropoietin resistance, malnutrition, and increased mortality. A cutoff value of ferritin needs to be established for better interpretation.

Keywords: Chronic kidney disease, C-reactive protein, Ferritin, Hemodialysis, Inflammation, Iron/erythropoietin (EPO) therapy.

How to cite this article: Padwal MK, RaichurkarAV, Melinkeri RR. Serum Ferritin Levels in Patients of Chronic Kidney Disease on

\footnotetext{
${ }^{1}$ Professor and Head, ${ }^{2}$ Tutor, ${ }^{3}$ Professor

${ }^{1}$ Department of Biochemistry, Bharati Vidyapeeth Medical College, Pune, Maharashtra, India

${ }^{2,3}$ Department of Biochemistry, Bharati Vidyapeeth Deemed University Medical College, Pune, Maharashtra, India

Corresponding Author: Meghana K Padwal, Professor and Head, Department of Biochemistry, Bharati Vidyapeeth Medical College, Pune, Maharashtra, India, Phone: +919822601149, e-mail: parampadwal@gmail.com
}

Hemodialysis: A Need to Redefine Cutoff for Iron/Erythropoietin Therapy. Indian J Med Biochem 2018;22(2):95-99.

\section{Source of support: Nil}

Conflict of interest: None

\section{INTRODUCTION}

Anemia of end-stage renal disease can be managed relatively successfully by recombinant human erythropoietin (EPO). Serum ferritin concentration and iron saturation ratio are among the two most commonly used markers of iron status in maintenance dialysis patients. ${ }^{1}$

According to National Kidney Foundation (NKF) kidney disease and dialysis outcome quality initiative (K/DOQI) guidelines, the iron administration should be withheld for a serum ferritin level $>800 \mathrm{ng} / \mathrm{mL}$ in these patients, since such high ferritin levels may reflect iron overload. ${ }^{2}$

However, serum ferritin is also an acute phase reactant and can be increased in inflammation. ${ }^{3-5}$ Inflammation is quite common in maintenance dialysis patients, and its prevalence among maintenance hemodialysis (MHD) patients may be as high as 40 to $60 \%$. Hence, it is quite possible that high levels of serum ferritin are engendered by inflammation independently of iron stores. ${ }^{6}$

However, it is not clear whether serum ferritin is indeed significantly increased in inflammation at different levels of body iron in dialysis patients. Moreover, inflammation is closely related to protein-energy malnutrition in dialysis patients, and the simultaneous combination of these two conditions, also referred to as 'malnutritioninflammation complex syndrome' (MICS), is observed frequently in dialysis patients. ${ }^{6}$

Over past 15 years, there has been an exponential growth of knowledge in inflammation in CKD and end stage renal disease (ESRD), which laid to evaluation in our perception of inflammation as a novel risk factor for morbidity and mortality associated with CKD. ${ }^{7}$

Although the emergence of erythropoietin stimulating agents has a revolution the anemia management of $\mathrm{CKD}^{8}$ strategies to assess iron status have remained indistinct.

Ferritin though a reliable marker of body irons status, ${ }^{9}$ is also known to be influenced by non-iron related conditions 
such as inflammation, malnutrition, liver diseases, infection and malignancies. ${ }^{10}$

\section{MATERIALS AND METHODS}

This study was a prospective, cross-sectional type. It was conducted between 15th September 2015 to 31st August 2017 in University Medical College with tertiary care hospital. The study was approved by the institutional ethics community. The study group was comprised of a total of 240 participants. They were divided into three groups as follows:

\section{Group I: CKD on Hemodialysis with Iron/EPO Therapy}

Total of 80 cases of CKD on hemodialysis receiving Iron / EPO therapy.

\section{Group II: CKD on Hemodialysis without Iron/EPO Therapy}

Total of 80 cases of CKD on hemodialysis not receiving Iron/EPO therapy.

The diagnosis of CKD was based on their history, clinical examination and laboratory findings. These cases were from both the outpatient and inpatient departments of the hospital.

\section{Group III: Healthy Controls}

Total of 80 age and gender-matched healthy individuals visiting the outpatient department of the hospital for a routine check-up.

\section{Inclusion Criteria}

Total 240 participants above 40 to 65 years of both genders were enrolled. One-hundred and sixty cases were CKD on hemodialysis with or without Iron/EPO therapy.

\section{Exclusion Criteria}

Participants suffering from known disorders/diseases like:

- Cardiac, hepatic and other systemic diseases.

- Any endocrinological abnormalities like thyroid disorders, etc.

- $\mathrm{H} / \mathrm{O}$ or clinical evidence of hemochromatosis.

- H/O drug or alcohol abuse.

All participants after their written informed consent underwent detailed physical and clinical examination. About $3 \mathrm{~mL}$ of blood sample was collected by venepuncture with all aseptic precautions in plain and ethylenediaminetetraacetic acid (EDTA) vacutainers. After one hour, the serum was separated from plain vacutainer by centrifugation at $2500 \mathrm{rpm}$ for 5 minutes at room temperature. Serum was ensured to be free from hemolysis and turbidity. The whole blood collected in EDTA vacutainer was used for estimation of hemogram (Coulter LH750).

A separated serum sample was subjected towards estimation of parameters on different analysers (Table 1).

Table 1: Methods of Estimations

\begin{tabular}{|c|c|c|}
\hline Sr. no. & Parameters & Method \\
\hline 1. & Ferritin & $\begin{array}{l}\text { Chemiluminescent microparticle } \\
\text { immunoassay }\left(\mathrm{CMIA}^{\mathrm{A}}\right) \mathrm{Abott} \\
\text { architect i1000SR }^{11}\end{array}$ \\
\hline 2. & C-reactive protein & $\begin{array}{l}\text { Automated biochemistry } \\
\text { analyzer }^{2}\end{array}$ \\
\hline 3. & Hemogram & Coulter LH-750 \\
\hline 4. & Iron & $\begin{array}{l}\text { Automated biochemistry } \\
\text { analyzer }{ }^{13}\end{array}$ \\
\hline 5. & TIBC & $\begin{array}{l}\text { Automated biochemistry } \\
\text { analyzer }{ }^{14}\end{array}$ \\
\hline
\end{tabular}

\section{Statistical Analysis}

Data were statically analyzed by using Statistical Package for the Social Sciences (SPSS) software. Analysis of variance (ANOVA) with Tukey's post hoc test used for finding the statistical significance between the means and comparison of serum ferritin, CRP, total leukocyte count (TLC), hemoglobin, iron and total iron binding capacity (TIBC) in cases and controls. Pearson's correlation coefficient used to correlate the above parameters. Receiver operating characteristic (ROC) to find out a cutoff value of serum ferritin. A p-value $<0.05$ was considered statistically significant.

\section{OBSERVATIONS AND RESULTS}

The serum ferritin levels were significantly elevated in group I (1957.6 \pm 714.1$)$ and group II $(1063.5 \pm 478.6)$ as compared to group III (101.21 \pm 60.29$)$ (Table 2).

The CRP levels were significantly elevated in group I (104.6 \pm 70.8$)$ and group II $(74.9 \pm 55.8)$ as compared to group III $(3.7 \pm 0.9)$ (Table 2$)$,

Total leukocyte count was significantly elevated in group II (11669.88 \pm 6200.82$)$ as compared with group I $(8087.50 \pm 3697.36)$ and group III (7372.45 \pm 1833.22). (Table 2).

Hemoglobin concentration was significantly decreased in group I (9.42 \pm 1.48$)$ and group II $(9.31 \pm 1.83)$ as compared with group III (13.65 \pm 9.78$)$. Serum iron levels were significantly decreased in group I $(66.17 \pm 44.85)$ and group II (60.28 \pm 44.35$)$ as compared with group III $(85.45 \pm 42.91)$.

Serum TIBC levels were significantly decreased in group I (184.24 \pm 77.12$)$ and group II $(174.24 \pm 68.24)$ as compared with group III (322.95 \pm 77.93) (Table 3).

We also found statistically significant positive correlation of serum ferritin levels with CRP (r-value: 0.531, $\mathrm{p}$-value $<0.01)$ and negative correlation of serum ferritin levels with TIBC (r-value 0.463 and p-value: < 0.001) (Table 4). 
Table 2: Comparison of serum ferritin, CRP and TLC in study groups

\begin{tabular}{|c|c|c|c|}
\hline Group & $\begin{array}{l}\text { Ferritin } n g / m L \\
\text { Mean } \pm S D\end{array}$ & $\begin{array}{l}C R P m g / L \\
\text { Mean } \pm S D\end{array}$ & $\begin{array}{l}\text { TLC /cubic mm } \\
\text { Mean } \pm S D\end{array}$ \\
\hline \multicolumn{4}{|l|}{ Group I } \\
\hline CKD on hemodialysis with iron/EPO therapy & $1957.6 \pm 714.1$ & $104.6 \pm 70.8$ & $8087.50 \pm 3697.36$ \\
\hline \multicolumn{4}{|l|}{ Group II } \\
\hline CKD on hemodialysis without iron/EPO therapy & $1063.5 \pm 478.6$ & $74.9 \pm 55.8$ & $11669.88 \pm 6200.82$ \\
\hline \multicolumn{4}{|l|}{ Group III } \\
\hline Healthy controls & $101.21 \pm 60.29$ & $3.7 \pm 0.9$ & $7372.45 \pm 1833.22$ \\
\hline$p$-value & $<0.05$ & $<0.05$ & $<0.05$ \\
\hline
\end{tabular}

Table 3: Comparison of hemoglobin, iron and TIBC in study groups

\begin{tabular}{lllc}
\hline Group & $\begin{array}{l}\text { Hemoglobin } g \mathrm{~m} / \mathrm{dL} \\
\text { Mean } \pm S D\end{array}$ & $\begin{array}{l}\text { Iron } \mu \mathrm{g} / \mathrm{dL} \\
\text { Mean } \pm S D\end{array}$ & $\begin{array}{c}T / B C \mu g / d L \\
M e a n \pm S D\end{array}$ \\
\hline $\begin{array}{l}\text { Group I } \\
\text { CKD on hemodialysis with Iron/EPO therapy }\end{array}$ & $9.42 \pm 1.48$ & $66.17 \pm 44.85$ & $184.24 \pm 77.12$ \\
\hline $\begin{array}{l}\text { Group II } \\
\text { CKD on hemodialysis without Iron/EPO therapy }\end{array}$ & $9.31 \pm 1.83$ & $60.28 \pm 44.35$ & $174.24 \pm 68.24$ \\
\hline $\begin{array}{l}\text { Group III } \\
\text { Healthy controls } \\
\text { p-value }\end{array}$ & $13.65 \pm 9.78$ & $85.45 \pm 42.91$ & $322.95 \pm 77.93$ \\
\hline
\end{tabular}

Table 4: Correlation of serum ferritin levels with other parameters

\begin{tabular}{lllllll}
\hline Parameter & & CRP & TLC & $H b$ & Iron & TIBC \\
\hline Ferritin & Pearson correlation coefficient (r-value) & & & & \\
& 0.531 & 0.223 & -0.186 & -0.167 & -0.463 & \\
& p-value & $<0.01$ & 0.001 & 0.004 & 0.009 & $<0.001$ \\
\hline
\end{tabular}

Table 5: Receiver operating curve analysis for serum ferritin levels

\begin{tabular}{llllll}
\hline Parameter & Cutoff value & Sensitivity & $95 \% \mathrm{Cl}$ & Specificity & $95 \% \mathrm{Cl}$ \\
\hline Ferritin & $>985 \mathrm{ng} / \mathrm{mL}$ & 98.7 & $93.2-99.8$ & 68.7 & $57.4-78.6$ \\
\hline
\end{tabular}

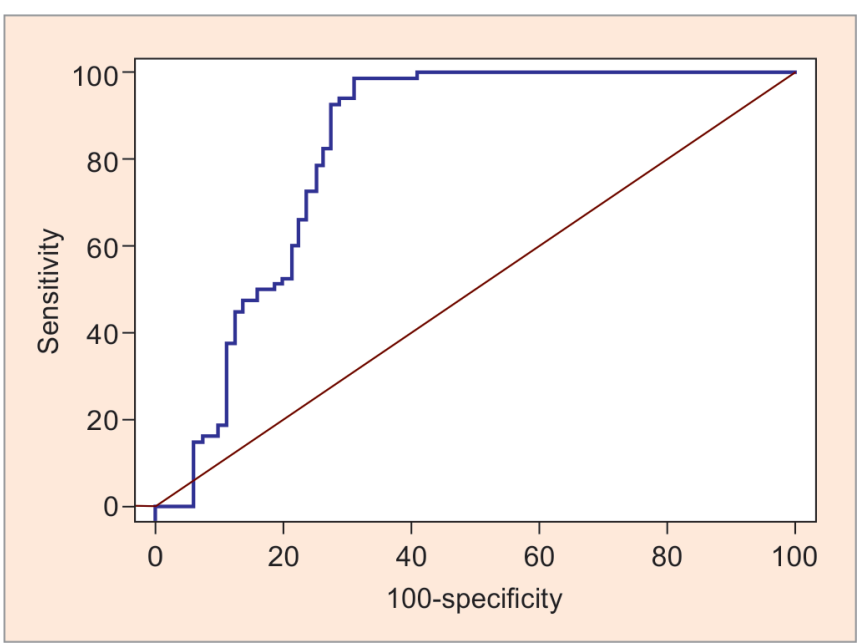

Graph 1: Receiver operating curve analysis for serum ferritin levels

We established a cutoff value of serum ferritin $>985$ $\mathrm{ng} / \mathrm{mL}$ in group I which may be associated with inflammation rather than iron overload (Table 5 and Graph 1).

\section{DISCUSSION}

The finding of our study indicates, significant positive correlation of markers of inflammation that is both serum ferritin and CRP (Fig. 1). A significant decrease in markers of iron status (indicated by low iron, TIBC and hemoglobin levels) are per various other studies. ${ }^{15-16}$

The finding of our study indicates, significant positive correlation of markers of inflammation that is both serum ferritin and CRP. A significant decrease in markers of iron status (indicated by low iron, TIBC and hemoglobin levels) are per various other studies. ${ }^{15-17}$

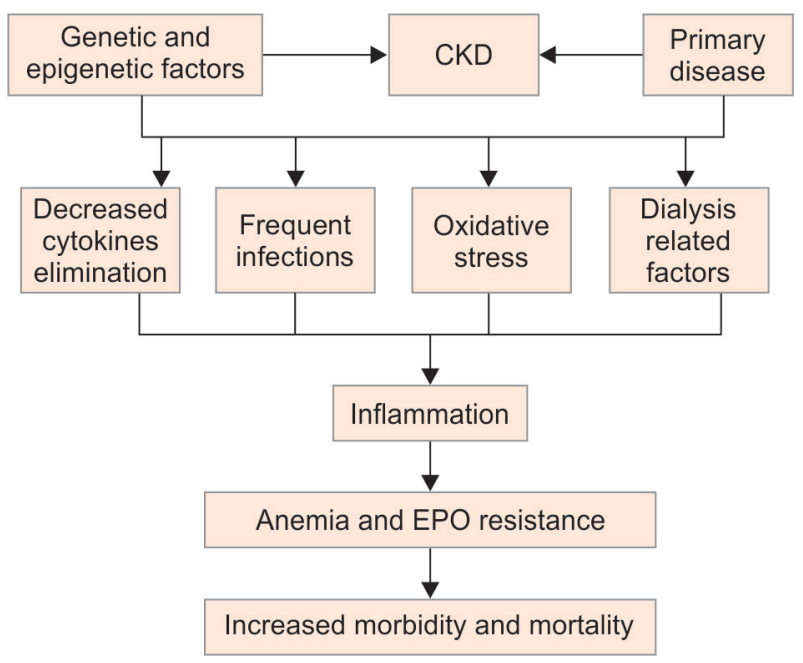

Fig. 1: Causes and consequences of inflammation in chronic kidney disease ${ }^{18}$ 
Therefore it is necessary to establish a cutoff level serum ferritin in patients of CKD on hemodialysis receiving iron/EPO therapy.

We established a cutoff value of serum ferritin $>985 \mathrm{ng} / \mathrm{mL}$ in group I which may be associated with inflammation rather than Iron overload. Figure $1^{17,18}$ depicts the causes and consequences of inflammation in chronic kidney disease.

Inflammation mediates the processes of monocyte influx, the proliferation of macrophages and matrix expansion, and results in glomerulosclerosis and tubulointerstitial injury which may further exacerbate kidney injuries. ${ }^{18,19}$

However, Roger's JT 20 stated that IL-1 $\beta$ induces ferritin gene expression by translational control of its messenger ribonucleic acid (mRNA).The inflammatory induction to occur of ferritin requires the background presence of cellular iron. Without adequate iron stores, serum ferritin is low and does not correlate with inflammation. ${ }^{21}$

Therefore as per their study findings with enough iron, serum ferritin is a marker of both iron storage and inflammation. However, this is in contradiction with our findings.

\section{Strengths and Limitation of Our Study}

Strengths of our study: Cross-sectional study design, Strict adherence to inclusion and exclusion criteria's and use of sensitive methods for the determination of serum ferritin, serum CRP, TLC, serum iron, and TIBC levels.

Limitation of our study: We have not taken in consideration the dietary intake of iron, status of other markers of inflammation like interleukins-6 (ILs-6), tumor necrosis factor- $\alpha$ and hs-CRP (a better measure than CRP) along with ferritin.

\section{CONCLUSION}

The significant increase in serum ferritin levels in patients of CKD on hemodialysis, may not always reflect iron overload.

This rise may be an inflammatory response as indicated by the significant positive correlation of serum ferritin with C-reactive protein and decreased iron, TIBC, and hemoglobin.

The cutoff value of serum ferritin $>985 \mathrm{ng} / \mathrm{mL}$ in group I may be associated with inflammation rather than iron overload.

The presence of inflammation may be responsible for erythropoietin resistance as documented by previous studies.

Strategies to dissociate inflammation from iron metabolism to mitigate the co founding impact of inflammation on the iron to improve the responsiveness of iron and EPO therapy may improve management of anemia in $\mathrm{CKD}$.

\section{Future Scope}

Longitudinal cross sectional cohort studies are required to observe the effect of hyperferritinemia with associate morbidity and mortality in patients of CKD.

To explore the potential therapeutic modalities for administrating anti cytokine agents which may prove useful to optimize EPO responsiveness.

\section{REFERENCES}

1. Joanne M, Skorecki BK. Disorders of the Kidney and Urinary Tract: Longo Fauci and Kasper Hauser. Harrison's Principles of Internal Medicine 18th ed. Part 13 Chapter 280 Chronic Kidney Disease. The McGraw-Hill companies. 2011;2: 2308-2316.

2. Levey AS, Coresh J, Bolton K, Culleton B, Harvey KS, Ikizler $\mathrm{TA}$, et al. K/DOQI clinical practice guidelines for chronic kidney disease: evaluation, classification, and stratification. American Journal of Kidney Diseases. 2002 Feb;39(2 SUPPL. 1): S1-S266.

3. Kalender B, Mutlu B, Ersoz M, Kalkan A, Yilmaz A. The effects of acute phase proteins on serum albumin, transferrin and haemoglobin in haemodialysis patients. Int J ClinPract. 2002; 56:505-508

4. Kalantar-Zadeh K, Don BR, Rodriguez RA, Humphreys $\mathrm{MH}$. Serum ferritin is a marker of morbidity of mortality in hemodialysis patients. American Journal of Kidney Diseases [Internet]. Elsevier BV; 2001 Mar;37(3):564-572.

5. Rogers JT. Ferritin translation by interleukin-1and interleukin-6: the role of sequences upstream of the start codons of the heavy and light subunit genes. Blood. 1996;87:2525-2537.

6. Kalantar-Zadeh K, Ikizler A, Block G, Avram M, Kopple J. Malnutrition-inflammation complex syndrome in dialysis patients: causes and consequences. Am J Kidney Dis. Am J Kidney Dis. 2003 Nov;42(5):864-881.

7. Kalantar-Zadeh K, Hoffken B, Wunsch H, Fink H, Kleiner M, Luft FC. Diagnosis of iron deficiency anemia in renal failure patients during the post erythropoietin era. Am J Kidney Dis 1995;26:292-299.

8. Ong DS, Wang L, Zhu Y, Ho B, Ding JL."The response of ferritin to LPS and acute phase of Pseudomonas infection. Journal of Endotoxin Research. 2005;11(5):267-280.

9. Krause JR, Stolc V. Serum Ferritin and Bone Marrow Iron Stores, Correlation with Absence of Iron in Biopsy Specimens. Am J Clin Pathol. 1979;72:817-820.

10. Kalantar-Zadeh K, Rodriguez RA, Humphreys MH. Association between serum ferritin and measures of inflammation, nutrition and iron in haemodialysis patients. Nephrol Dial Transplant. 2004;34:141-149.

11. Smith J, Osikowicz G. Abbott AxSYM random and continuous access immunoassay system for improved workflow in the clinical laboratory. Clinical chemistry. 1993 Oct 1;39(10): 2063-2069.

12. Siedel J, Wahlefeld AW, Ziegenhorn J. A new iron Ferrozine reagent without deproteinization. Clin Chem. 1984;30:975.

13. Siedel J et al. Clin Chem.1984;30:975. 
14. Tietz NW. Textbook of Clinical Chemistry. 3rd ed. Philadelphia, PA: WB Saunders. 1999;1821.

15. Maruyama $Y$, Yokoyama K. The Different Association between Serum Ferritin and Mortality in Hemodialysis and Peritoneal Dialysis Patients Using Japanese Nationwide Dialysis Registry. PLoS One. 2015;10(11):e0143430.

16. Gunnell J, Yeun JY, Depner TA, Kaysen GA. Acute-phase response predicts erythropoietin resistance in hemodialysis and peritoneal dialysis patients. American Journal of Kidney Diseases [Internet]. Elsevier BV; 1999 Jan;33(1):63-72.

17. Jennifer Gunnell, MD, Jane Y. Yeun.Acute-Phase Response Predicts Erythropoietin Resistance inHemodialysis and Peritoneal Dialysis PatientsAmerican Journal of Kidney Diseases.1999;33(1):63-72.

18. Akchurin OM, Kaskel F. Update on Inflammation in Chronic Kidney Disease. Blood Purification [Internet]. S. Karger AG; 2015 Jan 20;39(1-3):84-92.
19. Rogers JT, Bridges KR, Durmowicz GP, Glass J, Auron PE, Munro HN. Translational control during the acute phase response. Ferritin synthesis in response to interleukin-1. J Biol Chem. 1990 Aug 25;265(24):14572-14578.

20. Kim HJ, Vaziri ND. Contribution of impaired Nrf2-Keap1 pathway to oxidative stress and inflammation in chronic renal failure. American Journal of Physiology-Renal Physiology [Internet]. American Physiological Society; 2010 Mar;298(3): F662-F671.

21. Nassar GM. Preventing and Treating Inflammation: Role of Dialysis Access Management. Seminars in Dialysis [Internet]. Wiley; 2012 Oct 9;26(1):28-30.

22. Friedrich B, Alexander D, Janessa A, Häring H-U, Lang F, Risler T. Acute effects of hemodialysis on cytokine transcription profiles: Evidence for C-reactive protein-dependency of mediator induction. Kidney International [Internet]. Elsevier BV; 2006 Dec;70(12):2124-2130. 